\title{
Exendin-4 Induces Bone Marrow Stromal Cells Migration Through Bone Marrow- Derived Macrophages Polarization via PKA-STAT3 Signaling Pathway
}

\author{
Ning Wang ${ }^{a}$ Jian Gao Min Jia $^{a} \quad$ Xue Ma ${ }^{a}$ Zhanxiang Lei ${ }^{b} \quad$ Fei Da ${ }^{a}$ \\ Fei Yanc Huinan Zhanga Ying Zhou ${ }^{a}$ Mingkai Lia Gonghao He ${ }^{d}$ \\ Jingru Meng ${ }^{a}$ Xiaoxing Luo ${ }^{a}$ \\ aDepartment of Pharmacology, School of Pharmacy, Fourth Military Medical University, Xi'an, \\ Shaanxi; ${ }^{b}$ Clinical laboratory center, Hospital No. 159 of P.L.A, Zhumadian, Henan; 'Department \\ of Pharmacogenomics, School of Pharmacy, Fourth Military Medical University, Xi'an, Shaanxi; \\ dDepartment of Pharmacy, Kunming General Hospital of Chengdu Military Region, Kunming, Yunnan, \\ China
}

\section{Key Words}

Exendin-4 $\bullet$ Macrophage $\cdot$ TGF- $\beta 1 \cdot$ Polarization $•$ Migration

\begin{abstract}
Background/Aims: The synthesis and degradation processes involved in bone remodeling are critically regulated by osteoblasts and osteoclasts. The GLP-1 receptor agonist Exendin-4 is beneficial for osteoblast differentiation and increases the number of osteoblasts. Methods: We constructed an ovariectomized model to evaluate the impact of Exendin-4 on bone formation in osteoporosis. A macrophage-depleted model was also created to investigate the effect of macrophages on bone formation. Thirty-two female WT C57BL/6 mice (aged 3 months) were randomly assigned to a normal control group and four ovariectomized (OVX) subgroups: OVX + vehicle group, OVX + Exendin-4 (4.2 $\mu \mathrm{g} / \mathrm{kg} /$ day) group, OVX + chloride phosphate liposome group and OVX + chloride phosphate liposome + Exendin-4 group. Results: In this study, we found that Exendin-4 not only increased the number of osteoblasts and decreased the number of osteoclasts, but also increased the number of bone marrow stromal cells (BMSCs) at the bone surface. Moreover, we found that OVX mice treated with Exendin-4 increased TGF- $\beta 1$ levels at the bone surface compared with that in OVX mice. Besides, Exendin-4 promoted the polarization of bone marrow-derived macrophages into M2 subtype and increased TGF- $\beta 1$ secretion by the M2 subtype. Finally, we found that Exendin-4 induced macrophage polarization via the CAMP-PKA-STAT3 signaling pathway. Conclusion: Exendin-4 promotes bone marrow-derived macrophage polarization to the $\mathrm{M} 2$ subtype and induces BMSC migration to the bone surface via PKA-STAT3 signaling.

(C) 2017 The Author(s)

Published by S. Karger AG, Basel

Jingru Meng

Department of Pharmacology, School of Pharmacy,

and Xiaoxing Luo

The Fourth Military Medical University, Xian 710032, (China)

E-Mailmjrfmmu@fmmu.edu.cn, xxluo3@fmmu.edu.cn
\end{abstract}




\section{Cellular Physiology Cell Physiol Biochem 2017;44:1696-1714 \\ \begin{tabular}{ll|l} 
and Biochemistry Publisned ontIne: December 06, 2017 & $\begin{array}{l}\text { (c) } 2017 \text { The Author(s). Published by S. Karger AG, Basel } \\
\text { www.karger.com/cpb }\end{array}$ \\
\hline
\end{tabular}}

Wang et al.: Exendin-4 Induces BMSC Migration Via BMDM Polarization

\section{Introduction}

Bone formation can be divided into two distinct processes: modeling and remodeling, with bone formed and resorbed [1]. Bone modeling is an uncoupled cooperation between osteoblasts and osteoclasts leading to mineral deposition and bone resorption at different bone surface locations. In contrast, bone remodeling is a coupled sequential process, in which the extracellular matrix is deposited by osteoblasts at specific anatomical locations due to osteoclast resorption [2]. Dysregulation of the balance between osteoblast formation and osteoclast resorption is associated with skeletal diseases such as osteoporosis, which is common in elderly people and postmenopausal women [3]. At present, the variety of therapies that are used to prevent osteoporosis and to improve bone mass can be divided into antiresorptive agents, such as alendronate, and anabolic agents, such as parathyroid hormone (PTH) [4-6]. Although it was speculated that combined therapies should be more effective, clinical trials have shown that the anabolic effects of PTH are impaired by the antiresorptive agents [4, 7]. Thus, an agent that not only promotes bone formation, but also inhibits bone resorption is urgently required.

Some studies have indicated soluble factors that are released during bone resorption by osteoclasts plays a vital role in bone formation. During resorption, many factors are released from the bone matrix, including insulin growth factor-1 (IGF-1), bone morphogenetic proteins (BMPs), platelet derived growth factor (PDGF) and transforming growth factor- $\beta 1$ (TGF- $\beta 1$ ) $[8,9]$. IGF induces differentiation of BMSC into osteoblasts and TGF- $\beta 1$ promotes BMSC migration into the resorption pits for new bone formation $[4,10,11]$ in a process known as bone remodeling. TGF- $\beta 1$ is one of the most abundant cytokines embedded in the bone matrix in an inactive state. The inactive molecule consists of latency-associated protein bound to active TGF- $\beta 1$ to form the latent complex [12]. Active TGF- $\beta 1$ released aberrantly from the bone resorptive sites by osteoclasts contributes to the pathogenesis of disorders such as osteoarthritis in the subchondral bone [10,13,14], chronic kidney disease (CKD) [15], benign prostatic hyperplasia (BPH) [16] and Camurati-Engelmann disease (CED) [9]. During the menopause in women, sexual hormone production is reduced with activation of osteoclasts and osteoblasts as a secondary effect. Consequently, bone formation does not compensate for bone resorption leading to osteoporosis. Estrogen negatively regulates osteoclast formation and function through TGF- $\beta$ [17].

Glucagon-like peptide 1 (GLP-1) is an incretin hormone secreted from intestinal L cells in response to meal ingestion. GLP-1 or GLP-1 analogs are effective for the management of type-2 diabetes (T2DM) and exhibit protective effects of pancreatic beta cell and peripheral tissues $[18,19]$. Sun demonstrated that Exendin-4 is beneficial for the preservation of bone formation in ovariectomized rats through the inhibition of adipogenesis and enhancement the osteoblastogenesis of BMSCs [20]. Liraglutide, another GLP-1 receptor agonist, also stimulates osteogenesis in ovariectomized rats [21]. However, the mechanisms are unknown. Our previous study demonstrated that Exendin-4 protects bone loss and fractures and promotes bone formation by inducing BMSC differentiation into osteoblasts, while inhibiting differentiation into adipocytes [3]. In addition, we proposed that the mechanism underlying the effect of Exendin- 4 is via the GLP-1 receptor and Wnt/ $\beta$-catenin signaling pathways. In addition, the PI3K/AKT signaling pathway is also involved in the differentiation of BMSCs and some studies have shown that the GLP-1R signaling pathway can prevent apoptosis and promote cell proliferation $[22,23]$. According to the remodeling process theory, osteoclasts absorb bone matrix to release TGF- $\beta 1$, which promote BMSC migration to the resorptive bone surface. Exendin-4 inhibited osteoclast activity in an ovariectomized mouse model. Although this effect indicated reduced secretion of TGF- $\beta 1$ from bone matrix, our results showed the opposite effect, with increased levels of TGF- $\beta 1$ observed in ovariectomized mice treated with Exendin-4 compared with those treated with vehicle alone. The mechanism underlying this effect remains to be elucidated.

Bone fracture is the latent threat associated with osteoporosis [24, 25]. The first stage of healing after fracture is inflammation, which leads to granulation tissue formation and 
disrupts the balance between bone loss and formation [26, 27]. Macrophages play a vital role in bone formation via the relationship between osteoclasts and osteoblasts and the secretion of inflammatory factors [28-32]. Macrophages are the important components in immunity and defense, and also exhibit plasticity and polarization, which are features of mononuclear macrophages [33-36]. Macrophages can be divided into resident macrophages and inflammatory populations [25]. Inflammatory macrophages can also be divided into the classically activated/inflammatory (M1) and alternatively activated/ regenerative (M2) subpopulations that are produced depending on the environment [37, 38]. The M1 phenotype macrophages express high levels of pro-inflammatory cytokines, which are induced by Toll-like receptor (TLR) ligands and lipopolysaccharide (LPS) and/ or interferon gamma (INF- $\gamma$ ), while M2 macrophages act as the anti-inflammatory subtype and are activated by interleukin (IL)-4, IL-13, or IL-10 [39, 40]. In vitro and in vivo studies of the effects of resident macrophages (osteomacs) on osteogenesis have been reported previously [31, 32, 40,41], although the role of bone marrow-derived macrophages on bone formation are unknown. Dipeptidyl peptidase-4 (DPP-4), which degrades GLP-1, induces a significant reduction in the expression of NLRP3, TLR4 and IL-1 $\beta$ in macrophages [42]. Our study showed that Exendin-4 influences the expression of inflammatory mediators and other cytokines in macrophages, although the specific macrophage subtype affected and the underlying mechanisms are unknown.

In this study, we hypothesized that Exendin-4 regulates the polarization of bone marrowderived macrophages (BMDMs) to induce BMSC migration to the bone surface. To test our hypothesis, we investigated the effect of Exendin-4 on macrophages and bone formation both in vitro and in vivo. Our results indicated that Exendin-4 regulates BMDM polarization into the M2 subtype and promotes TGF- $\beta 1$ secretion to promote BMSC migration to the bone surface. These findings indicate that GLP-1 and its analogs represent promising candidates for the treatment of osteoporosis.

\section{Materials and Methods}

\section{Ethics statement (mouse experiments)}

All animal studies were reviewed and approved by the Animal Care and Use Committee of the Fourth Military Medical University (Xi'an, China) and carried out in accordance with their guidelines.

\section{Animals}

Thirty-two female WT C57BL/6 mice (aged 3 months) were obtained from the Animal Center of Fourth Military Medical University (Xi'an, China). Mice were randomly assigned to a normal control group and four ovariectomized (OVX) subgroups: OVX + vehicle group, OVX + Exendin-4 (4.2 $\mu \mathrm{g} / \mathrm{kg} / \mathrm{day}$ ) group, OVX + clodronate liposomes group and OVX + clodronate liposomes + Exendin-4 group. At 4 weeks after surgery, each group was treated appropriately for 2 months by intraperitoneal administration. The doses of Exendin-4 were selected based on the results of our previous study [3].

Mice weights were recorded weekly during the 2-month experimental period. Subsequently, trabecular bone microarchitecture in femurs was analyzed by micro-computed tomography (micro-CT). Mice were then sacrificed for analysis of gene and protein expression in the femurs and vertebra. Tibiae were fixed in $4 \%$ paraformaldehyde (PFA), decalcified in 10\% ethylenediamine tetra-acetic acid (EDTA, pH 7.0), and then embedded in paraffin. Longitudinal sections (5- $\mu$ m thick) were stained with anti-COL- I antibody to count osteoblasts and with tartrate-resistant acid phosphatase (TRAP) to visualize bone marrow osteoclasts. All animal studies were reviewed and approved by the Animal Care and Use Committee of the Fourth Military Medical University (Xi'an, China) and carried out in accordance with their guidelines.

\section{Micro-CT imaging}

Mice were anesthetized with 5\% chloral hydrate and positioned for micro-CT scanning of the microarchitecture of whole femurs. The images were reconstructed to an isotropic voxel size of $10 \mu \mathrm{m}$. Bone volume/total volume, bone surface area/bone volume, trabecular thickness, trabecular number, and 


\section{Cellular Physiology Cell Physiol Biochem 2017;44:1696-1714 \begin{tabular}{l|l|l} 
and Biochemistry 10.1159/000485776 & $\begin{array}{l}\text { C) } 2017 \text { The Author(s). Published by S. Karger AG, Basel } \\
\text { www.karger.com/cpb }\end{array}$
\end{tabular}}

Wang et al.: Exendin-4 Induces BMSC Migration Via BMDM Polarization

trabecular spacing were calculated and three-dimensional image manipulations were performed by the system software (Inveon Research Workplace 2.2, SIEMENS Healthineers).

\section{Immunohistochemistry}

Femurs were fixed in 4\% PFA and decalcified in 10\% EDTA (pH 7.0) for 30 days prior to embedding in paraffin. Samples for immunohistochemical (IHC) analysis were deparaffinized and rehydrated according to standard protocols. Samples were incubated with the relevant primary detection antibodies: rabbit polyclonal anti-TGF $\beta 1$ (ab92486; $20 \mu \mathrm{g} / \mathrm{ml}$; Abcam, Cambridge, MA, USA), rabbit polyclonal anti-CD68 (ab125212; $1 \mu \mathrm{g} / \mathrm{ml}$; Abcam) overnight at $4^{\circ} \mathrm{C}$. The samples were washed three times in PBS (3 minutes each wash), and incubated with biotin-conjugated goat anti-rabbit IgG secondary antibody (Zhongshanjinqiao, Beijing) for 30 min. Images were acquired using an Olympus BX53 microscope (Olympus, Tokyo, Japan). We selected at least five images from each section per femur to measure the density of TGF- $\beta 1$ or the numbers of CD68-positive cells.

\section{Isolation of bone marrow-derived macrophages and bone marrow stromal cells}

BMDMs were isolated from mice and characterized using established approaches described in previous reports. In brief, the cells isolated from femurs and tibias were cultured in H-DMEM containing $10 \%$ fetal bovine serum (FBS), $100 \mathrm{U} / \mathrm{ml}$ penicillin, $100 \mathrm{mg} / \mathrm{ml}$ streptomycin sulfate (Gibco) at $37^{\circ} \mathrm{C}$ in a $5 \% \mathrm{CO}_{2}$ humidified incubator. After $6 \mathrm{~h}$, adherent cells were removed and non-adherent bone marrow cells were centrifuged at 1, $000 \mathrm{rpm}$ for $5 \mathrm{~min}$ at $4^{\circ} \mathrm{C}$ and then cultured with H-DMEM containing macrophage colonystimulating factor (25 ng/ml) in 24-wells plate for 7 days. Macrophages were characterized by Western blotting and RT-PCR analyses.

BMSCs were isolated from the femurs and tibias of 5-week-old C57BL/6 male mice. The cells were collected in H-DMEM culture medium supplemented with 10\% FBS (Gibco), $100 \mathrm{U} / \mathrm{ml}$ penicillin, $100 \mathrm{mg} /$ $\mathrm{ml}$ streptomycin and cultured at $37^{\circ} \mathrm{C}$ in a humidified atmosphere under $5 \% \mathrm{CO}_{2}$. Flow cytometric analysis showed that the isolated BMSCs were a relatively pure population of stromal cells that were negative for CD34, CD45 and positive for CD29, Sca-1.

\section{Characterization of macrophage phenotype}

Macrophages collected 7 days after differentiation from monocytes were regarded as the M0 population, which were characterized by the expression of F4/80+ and CD11b markers. After stimulation with IL-4 or LPS+INF- $\gamma$, macrophages were polarized into the M1 or M2 populations, respectively. The M1 population was characterized by the expression of inducible nitric oxide synthase (iNOS) and TNF- $\alpha$, while the M2 population was characterized by the expression of ARG and mannose receptor 1 (MRC-1).

\section{RNA extraction and quantitative real-time PCR analysis}

Total RNA was isolated from macrophages or bone fragments using TRIzol reagents (Invitrogen). cDNA was prepared using the One Step SYBR $®$ PrimeScript ${ }^{\mathrm{TM}}$ RT-PCR Kit (TaKaRa) according to the manufacturer's instructions. Quantitative real-time PCR was performed using the SYBR® Premix Ex Taq ${ }^{\text {TM }}$ (TaKaRa) in a Bio-Rad CFX96 ${ }^{\mathrm{TM}}$ real-time PCR detection system (Bio-Rad) with the following thermocycling conditions: denaturation at $95^{\circ} \mathrm{C}$ for $5 \mathrm{~s}$, followed by 40 cycles of denaturation at $95^{\circ} \mathrm{C}$ for $10 \mathrm{~s}$ and annealing at $57^{\circ} \mathrm{C}$ for $30 \mathrm{~s}$. Detection of the fluorescent product was carried out at the end of the $72^{\circ} \mathrm{C}$ extension incubation. PCR products were subjected to a melting curve analysis, and relative expression was calculated for each gene by the $2^{-\triangle \triangle C T}$ method following normalization against GAPDH expression. Each sample was tested at least in triplicate and repeated using three independent cell preparations (Table 1).

Western blot analysis

After stimulation by different factors for 3 days, macrophages were harvested for Western blot analysis. Cells were lysed in RIPA buffer (10 mM Tris-HCl, 1 mM EDTA, 1\% sodium dodecyl sulfate (SDS), 1:100 proteinase inhibitor cocktail, $50 \mathrm{mM} \beta$-glycerophosphate, $50 \mathrm{mM}$ sodium fluoride). Briefly, whole cell lysates were separated by $10 \%$ SDS-polyacrylamide gel electrophoresis and transferred to a PVDF membrane. The membranes were blocked with $5 \%$ non-fat milk for $2 \mathrm{~h}$ and incubated overnight at $4{ }^{\circ} \mathrm{C}$ with the following primary detection antibodies: rabbit polyclonal anti-TGF $\beta 1$ (ab92486; $20 \mu \mathrm{g} / \mathrm{ml}$; Abcam), rabbit polyclonal anti-iNOS (ab204017; 1 g/ml; Abcam), rabbit polyclonal anti-ARG 3.1 (ab203056; 1:1, 000; Abcam), rabbit 


\section{Cellular Physiology Cell Physiol Biochem 2017;44:1696-1714

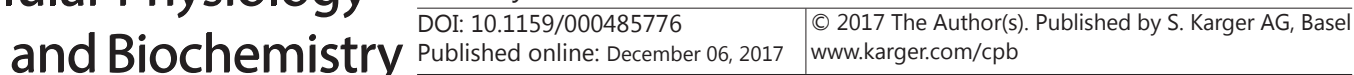

Wang et al.: Exendin-4 Induces BMSC Migration Via BMDM Polarization

Table 1. Oligonucleotide primers used for real-time PCR

\begin{tabular}{lcc}
\hline Gene & Primers & Primer sequence (5'-3') \\
\hline \multirow{2}{*}{ TGF-beta 1} & forward & $5^{\prime}$-TGGCCAGATCCTGTCCAAAC-3' \\
& reverse & $5^{\prime}$-GCGGGTGACCTCTTTAGCAT-3' \\
fNOS & forward & $5^{\prime}$-CAgCggAgTgACggCAAACAT-3' \\
& reverse & $5^{\prime}$-gCAAgACCAgAggCAgCACATC-3' \\
Arg 1 & forward & $5^{\prime}$-ggCAAggAAAggAATggTgggA-3' \\
& reverse & $5^{\prime}$-TggTTgTgAgTggTTgggAggA-3' \\
MRC & forward & $5^{\prime}$-TgTCACggAgATCCACgAgCAA-3' \\
& reverse & $5^{\prime}$-CTgCCAACCACTgCgTACACTC-3' \\
Gapdh & forward & $5^{\prime}$-gCTgAgTATgTCgTggAgT-3' \\
& reverse & $5^{\prime}$-gTTCACACCCATCACAAAC-3' \\
\hline
\end{tabular}

polyclonal anti-PKA c- $\alpha$ (\#4782; 1:1, 000; Cell Signaling), rabbit monoclonal anti-phospho-stat3 (Tyr705) (\#7145; 1:1, 000; Cell Signaling). Membranes were then incubated with HRP-conjugated secondary antibodies: anti-rabbit IgG (1:1, 0000, Boster Bio-Technology, Wuhan, China) and anti-mouse IgG (Boster Bio-Technology). Immunoreactive bands were detected using enhanced chemiluminescence (ECL, GE Healthcare Pharmacia). Densitometric analysis of Western blots was conducted using a ChemiDoc XRS (BioRad, Hercules, CA, USA) and quantified using Quantity One version 4.1.0 (Bio-Rad).

\section{ELISA}

Cells were incubated in a 24-well plate and treated with stimulatory factors as indicated. Supernatants were collected and frozen at $-80^{\circ} \mathrm{C}$ before analysis by enzyme-linked immunosorbent assays (ELISA). Secreted M1 markers were tumor necrosis factor-alpha (TNF- $\alpha$ ) and iNOS and M2 markers were IL-1ra and MRC. Supernatant levels of the M1 marker TNF- $\alpha$ and the M2 marker IL-1ra were analyzed using ELISA kits (329946 and 328852, respectively; R\&D) following the manufacturer's instructions. Active levels of TGF- $\beta 1$ markers were analyzed using ELISA kits (L160229821; Cloud-Clone Corp.) following the manufacturer's instructions.

\section{SiRNA transfection}

The effects of GLP-1R on macrophages or TGF- $\beta 1$ secreted by macrophages were determined by siRNAmediated knockdown of the relevant gene expression in macrophages. Macrophages $\left(5 \times 10^{5} / \mathrm{ml}\right)$ were cultured to $60 \%-80 \%$ confluence and then seeded in 24 well plates and transfected with GLP-1R siRNA or TGF- $\beta 1$ siRNA using Lipofectamine RNAiMAX Reagent (13778075, Invitrogen) in Opti-MEM medium. The siRNA was diluted in Opti-MEM medium and mixed with Lipofectamine RNAiMAX Reagent at a ratio of 1:1.

\section{Migration assay}

Cell migration was investigated in Transwell assays. BMSCs were seeded into the upper compartment of a Transwell plate and the macrophages were seeded into the lower compartment. Cells were randomly assigned into the following groups: macrophages, macrophages+IL-4 (20 ng/ml), macrophages+Exendin-4 $\left(10^{-7} \mathrm{M}\right)$, macrophages+LPS $(25 \mathrm{ng} / \mathrm{ml})+\mathrm{INF}-\gamma(100 \mathrm{ng} / \mathrm{ml})$, macrophages+IL-10 (10 ng/ml), TGF- $\beta 1$ (1 ng/ $\mathrm{ml})$, and TGF- $\beta 1$ neutralizing antibody $(0.5 \mu \mathrm{g} / \mathrm{ml})$. After incubation at $37^{\circ} \mathrm{C}$ for $24 \mathrm{~h}$, the culture media in the upper and lower compartments were collected. The filters were fixed in $4 \%$ paraformaldehyde for 20 min and stained with $0.1 \%$ crystal violet for $15 \mathrm{~min}$. The number of migrated cells was counted in five fields under the Olympus BX53 microscope (Olympus, Tokyo, Japan).

Co-immunoprecipitation

Total proteins were extracted from BMDMs using NP-40 lysis buffer (Beyotime). The extract was preincubated with protein A/G PLUS-agarose (Santa Cruz Biotechnology, Dallas, TX, USA) and normal rabbit IgG antibodies for $30 \mathrm{~min}$ at $4^{\circ} \mathrm{C}$. The mixture was then centrifuged at 2, $500 \mathrm{rpm}$ for $5 \mathrm{~min}$ at $4^{\circ} \mathrm{C}$. Phospho- 


\section{Cellular Physiology Cell Physiol Biochem 2017;44:1696-1714 \\ \begin{tabular}{ll|l} 
and Biochemistry Publisned ontIne: December 06, 2017 & $\begin{array}{l}\text { (c) } 2017 \text { The Author(s). Published by S. Karger AG, Basel } \\
\text { www.karger.com/cpb }\end{array}$ \\
\hline
\end{tabular}}

Wang et al.: Exendin-4 Induces BMSC Migration Via BMDM Polarization

PKA substrate antibody (1:50; Cell Signaling Technology) and protein A/G PLUS-agarose were added to the supernatants and incubated for $1 \mathrm{~h}$. The mixture was centrifuged for $5 \mathrm{~min}$ and the immunoprecipitates were eluted using a protein sample buffer. The immunoprecipitates were separated by SDS-PAGE and analyzed by immunoblotting using antibodies against PKAc and P-STAT3 (Cell Signaling Technology).

\section{Statistical analysis}

All data were expressed as means \pm standard deviation (SD) of at least three independent experiments and analyzed using SPSS for Windows, version 15.0. Statistical significance was determined by one-way ANOVA followed by post-hoc multiple comparisons using a Student-Newman-Keuls $t$-test. $P<0.05$ was considered to indicate statistical significance.

\section{Results}

GLP-1 receptor agonist Exendin-4 stimulates bone formation in ovariectomized mice

The protective effect of Exendin- 4 on bone mass loss was investigated in ovariectomyinduced osteoporosis mice, which is characterized by estrogen deficiency. The femurs of mice in the control group, OVX group, and OVX with Exendin-4 (4.2 $\mu \mathrm{g} / \mathrm{kg} /$ day) group were analyzed using micro-computed tomography (micro-CT) (Fig. 1A). The trabecular bone was markedly improved in Exendin-4-treated mice compared to that of the OVX mice. Furthermore, the ratio of bone volume to total volume (BV/TV) and trabecular number (Tb.N) in the OVX mice treated with Exendin-4 was higher than that of the OVX mice (Fig. $1 \mathrm{~B}, \mathrm{C})$. These results showed that Exendin-4 improves the structure of trabecular bone leading to improvements in bone mass.

To further explore the effect of Exendin-4 on osteogenesis, we used double calcein and tetracycline labeling to monitor bone formation parameters and determine how Exendin-4 retarded the bone loss caused by the osteoporosis (Fig. 1D). The results showed that Exendin-4 increased mineral deposition at the bone surface and promoted new bone formation compared to that in OVX mice.

The expression of Runt-related transcription factor 2 (Runx-2) and Osterix, which represent markers of osteogenesis progression, were examined by Western blotting to assess the ability of Exendin-4 to promote osteogenesis (Fig. 1E-G). Compared to the OVX mice, higher levels of Runx-2 and Osterix were detected in bone tissue of the OVX mice treated with Exendin-4, indicating that Exendin-4 promotes osteoblast differentiation and osteogenesis. Furthermore, immunohistochemical staining of osteocalcin showed increased numbers of osteoblasts on the bone surface in the OVX mice treated with Exendin-4 compared with those in the OVX mice (Fig. 2A, B). Moreover, there were fewer osteoblasts in OVX mice compared with those in the control mice. Osteoblasts differentiate from BMSCs; however, a unique marker of BMSCs remains to be identified. Therefore, in this study, we detected BMSCs by immunostaining of CD29 and Sca-1 (Fig. 2C-E). The immunostaining showed abundant BMSCs attracted to the bone surface in the OVX mice compared with control mice. Greater numbers of BMSCs were detected in the OVX mice treated with Exendin-4 compared with those in the OVX mice. Cao [9] reported that TGF- $\beta 1$ is regarded as an essential migratory factor in the recruitment of BMSCs to the resorptive sites. The immunostaining results showed higher expression of TGF- $\beta 1$ in OVX mice compared with that in the control mice, while lower levels of TGF- $\beta 1$ in OVX mice compared with that in the OVX mice treated with Exendin-4 (Fig. $2 F$ ). Moreover, Western blot and qRT-PCR analyses showed that Exendin- 4 increased TGF- $\beta 1$ expression in OVX mice (Fig. 2G, H). TGF- $\beta 1$ is secreted mainly by osteoblasts and TGF- $\beta 1$ embeds in the bone matrix with collagen I . Osteoclasts absorb the bone matrix to release active TGF- $\beta 1$, which induces BMSC migration to resorptive sites [9]. The immunostaining revealed fewer osteoclasts in the OVX mice treated with Exendin-4 compared with the OVX mice, suggesting that Exendin-4 decreased the numbers of osteoclasts (Fig. 2I, J). According to these results showing few osteoclasts in OVX mice treated with Exendin-4, it would be expected that the levels of TGF- $\beta 1$ should be correspondingly low. However, higher levels of 


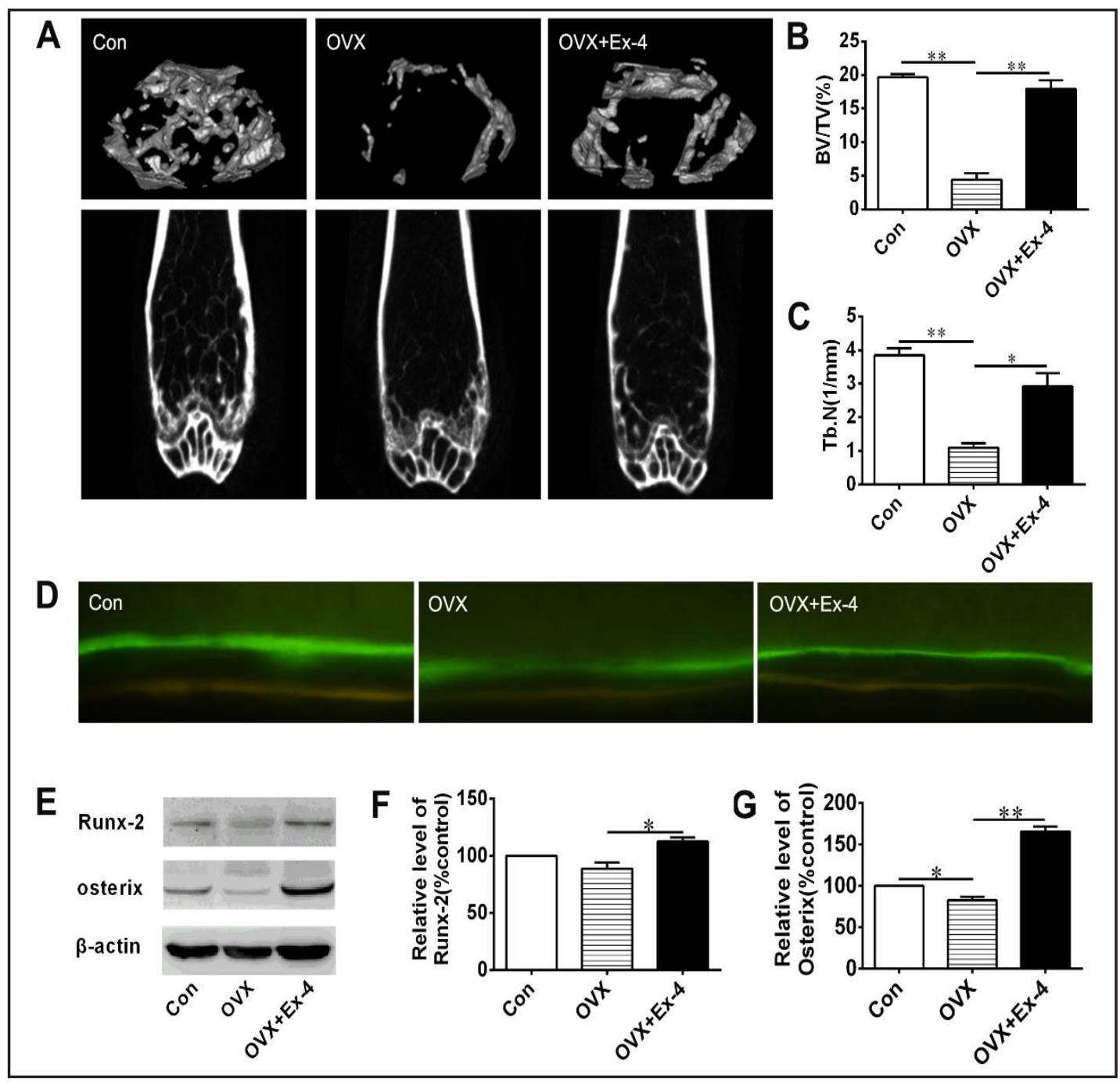

Fig. 1. Exendin-4 promoted bone formation in OVX mice. (A) Micro-CT reconstruction of distal femoral metaphyseal regions from Control, OVX and OVX mice treated with Exendin-4 ( $\mathrm{n}=6$ independent samples/ group). (B, C) BV/TV and Tb.N determined by micro-CT analysis. BV/TV, bone volume/ tissue volume; Tb.N, trabecular number.(D) Calcein and tetracycline labeling of the femur in the mice treated with vehicle or Exendin-4 ( $n=3$ independent samples/group). Scale bars, $10 \mu \mathrm{m}$. (E, F) Dynamic bone histomorphometric parameters in the femur trabecular bone sections ( $n=3$ independent samples/group). MAR, mineral apposition rate; BFR/BS, bone formation rates/bone surface area. (G) Western blot analysis of Runx-2 and Osterix protein levels in mouse bone tissues ( $\mathrm{n}=3$ independent samples/group). Data represent the mean \pm SD. Differences between groups were evaluated by one-way ANOVA followed by Student-Newman-Keuls t-test. $* \mathrm{P}<0.05,{ }^{* *} \mathrm{P}<0.01$.

TGF- $\beta 1$ were detected in OVX mice treated with Exendin- 4 compared with that in OVX mice; the mechanisms underlying this perplexing observation remain to be clarified.

\section{Bone marrow-derived macrophages are essential for bone formation in OVX mice}

Bone formation is a complex process involving the interaction between skeletal bone and the immune system. Macrophages are the main component in immunity and can be stimulated into osteoclasts. Thus, we detected macrophages in bone to determine differences in numbers among the groups. CD68 immunohistochemical analysis (Fig. 3A, B) showed that greater numbers of macrophages were detected on the trabecular bone surface in the OVX mice treated with or without Exendin-4 than that in the WT mice. Furthermore, there 
Fig. 2. Exendin-4 increased the numbers of osteoblasts and BMSCs as well as TGF- $\beta 1$ levels in bone tissues .(A, B) OCN immunohistochemistry (arrows indicate osteoblasts) and the numbers of osteoblasts in bone tissues. No. of $\mathrm{OB} / \mathrm{FV}$, number of osteoblasts per field of view ( $\mathrm{n}=3$ independent samples/group). Scale bars, $20 \mu \mathrm{m}$. (CE) Immunostaining of BMSCs in the bone tissues(C: CD29, D: Sca-1) ( $n=3$ independent samples/group). Scale bars, $20 \mu \mathrm{m}$.(F) Immunostaining of TGF- $\beta 1$ in the bone tissues ( $\mathrm{n}=3$ independent samples/group) (arrows indicate TGF- $\beta 1$ in the trabecular bone). Scale bars, $20 \mu \mathrm{m} .(\mathrm{G}, \mathrm{H})$ Western blot (G) and quantitative real-time-PCR $(\mathrm{H})$ analysis of TGF- $\beta 1$ expression in bone tissues from control, OVX and Exendin-4 mice (n = 3 independent sam-

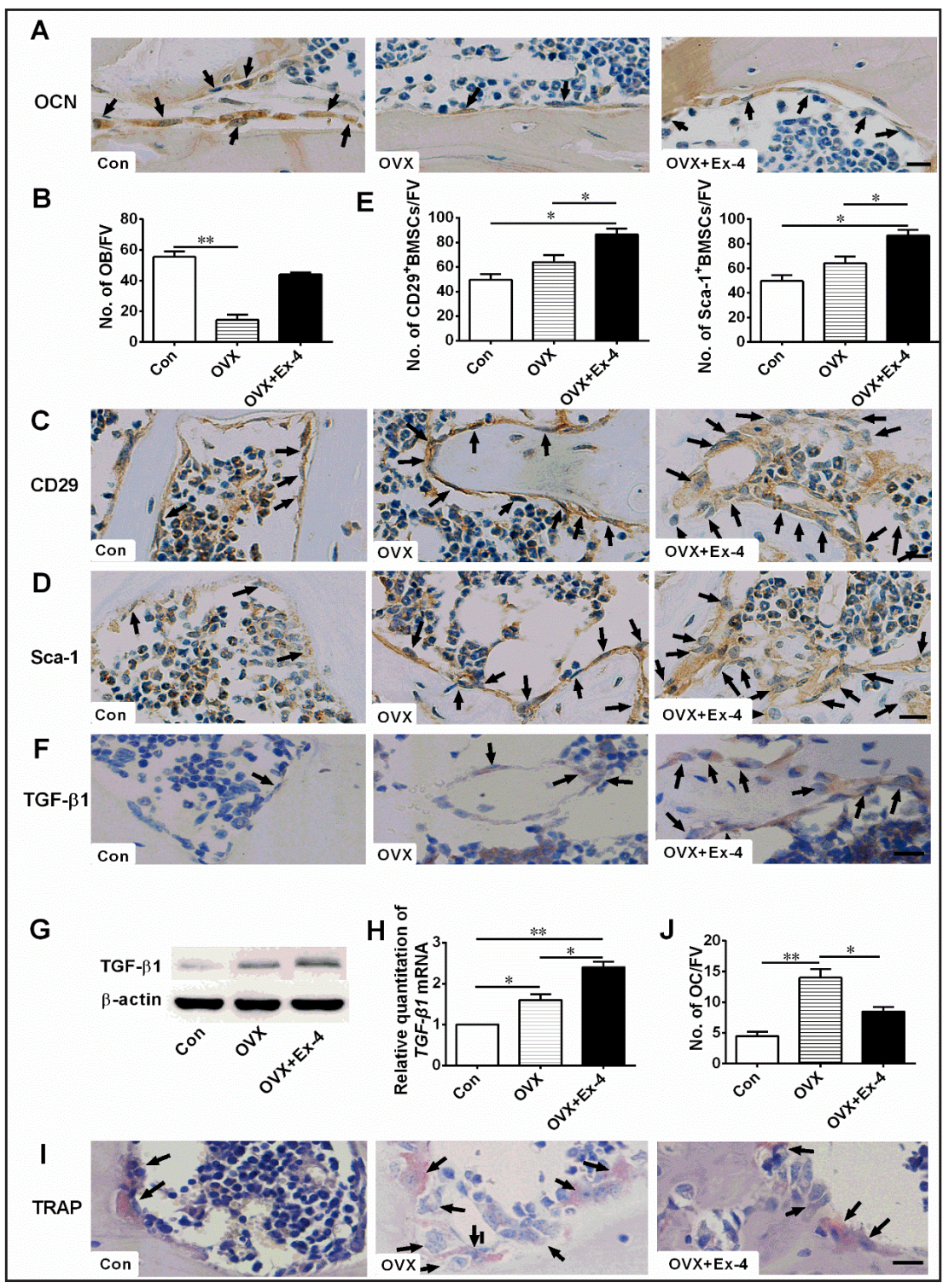
ples/group). (I, J) TRAP staining (arrows indicate osteoclasts) of bone tissues and the numbers of osteoclasts in the bone tissues from control, OVX and Exendin-4 mice ( $\mathrm{n}=3$ /independent samples/group). Scale bars, $20 \mu \mathrm{m}$. Data represent the mean \pm SD. Differences between groups were evaluated by one-way ANOVA followed by Student-Newman-Keuls t-test. ${ }^{*} \mathrm{P}<0.05$.

were greater numbers of CD206 positive macrophages on the bone surface in the OVX mice treated with Exendin-4 compared with that in the OVX mice (data not shown). These results indicated that macrophages participate in bone formation and might be affected by Exendin-4 although the mechanisms are unknown. To further determine the effects of macrophages on bone formation in osteoporosis, we used clodronate liposomes to eliminate the bone marrow-derived macrophages. Immunohistochemical analysis showed fewer macrophages in both OVX mice administered with clodronate liposomes and OVX mice administered with clodronate liposomes and Exendin-4 groups than in the other groups, thus, confirming that macrophages were partially depleted by clodronate liposome treatment (Fig. 3A,B).

Micro-CT imaging (Fig. 3C, D) showed that the bone mass (BV/TV), Tb.Th and Tb.N in the OVX mice treated with clodronate liposomes was lower than that in the control group. The bone mass (BV/TV), Tb.Th and Tb.N in the OVX mice treated with Exendin-4 and 


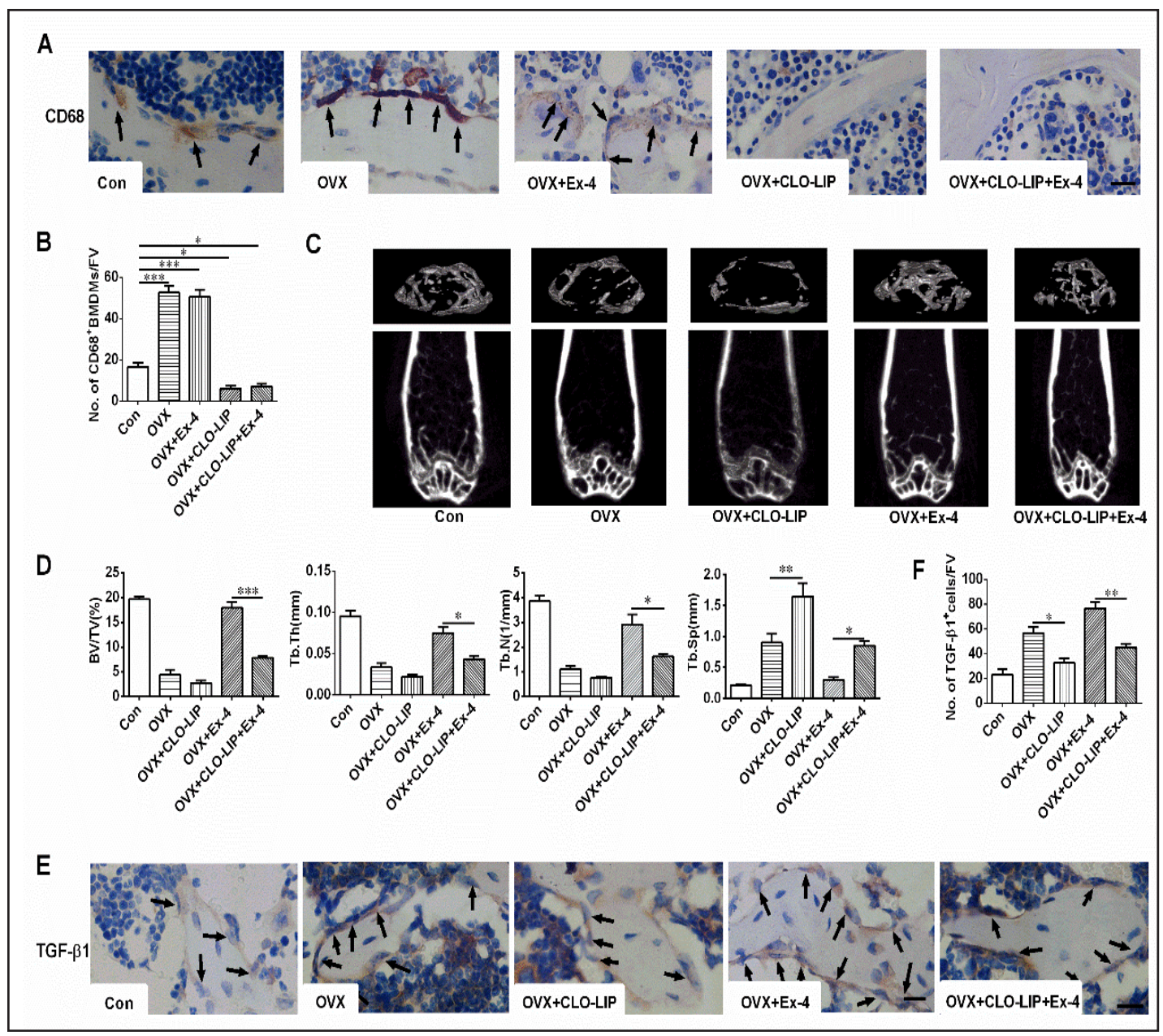

Fig. 3. Macrophages were essential for bone formation. (A,B) Immunostaining of macrophages (arrows indicate CD68 positive cells) in the trabecular bone ( $\mathrm{n}=3$ independent samples/group). Scale bars, $20 \mu \mathrm{m}$. (C) Micro-CT reconstruction of distal femoral metaphyseal regions ( $\mathrm{n}=6 /$ independent samples/group). CLO-LIP, clodronate liposomes. (D) Micro-CT analysis of distal femoral metaphyseal regions from the groups of mice indicated above ( $n=6 /$ independent samples/group). BV/TV, bone volume/total volume; Tb.N, trabecular number; Tb.Th, trabecular thickness; Tb.Sp, trabecular separation. (E,F) Immunostaining of TGF- $\beta 1$ (arrow indicated TGF- $\beta 1$ in the trabecular bone) in the bone tissues from the mice $(\mathrm{n}=3$ / independent samples/group). Scale bars, $20 \mu \mathrm{m}$. Data represent the mean $\pm \mathrm{SD}$. Differences between groups were evaluated by one-way ANOVA followed by Student-Newman-Keuls t-test. ${ }^{*} \mathrm{P}<0.05$.

clodronate liposomes was lower than that in the OVX mice treated with Exendin-4 alone. In addition, Tb.Sp in the OVX mice treated with clodronate liposomes was higher than that in the OVX mice group, and Tb.Sp in the OVX mice treated with Exendin- 4 and clodronate liposomes was higher than that in the OVX mice treated with Exendin-4 alone. This indicated that macrophages are involved in the mechanism by which Exendin-4 improves the bone mass, and that macrophages are essential for osteogenesis.

Furthermore, immunohistochemical analysis showed that the TGF- $\beta 1$ expression in OVX mice treated with clodronate liposomes was lower than that in the OVX and that the TGF- $\beta 1$ expression in OVX mice treated with clodronate liposomes and Exendin- 4 was lower than that in the OVX mice treated with Exendin-4 (Fig. 3E, F). These results indicated that macrophages influence TGF- $\beta 1$ secretion and bone formation in OVX mice. 


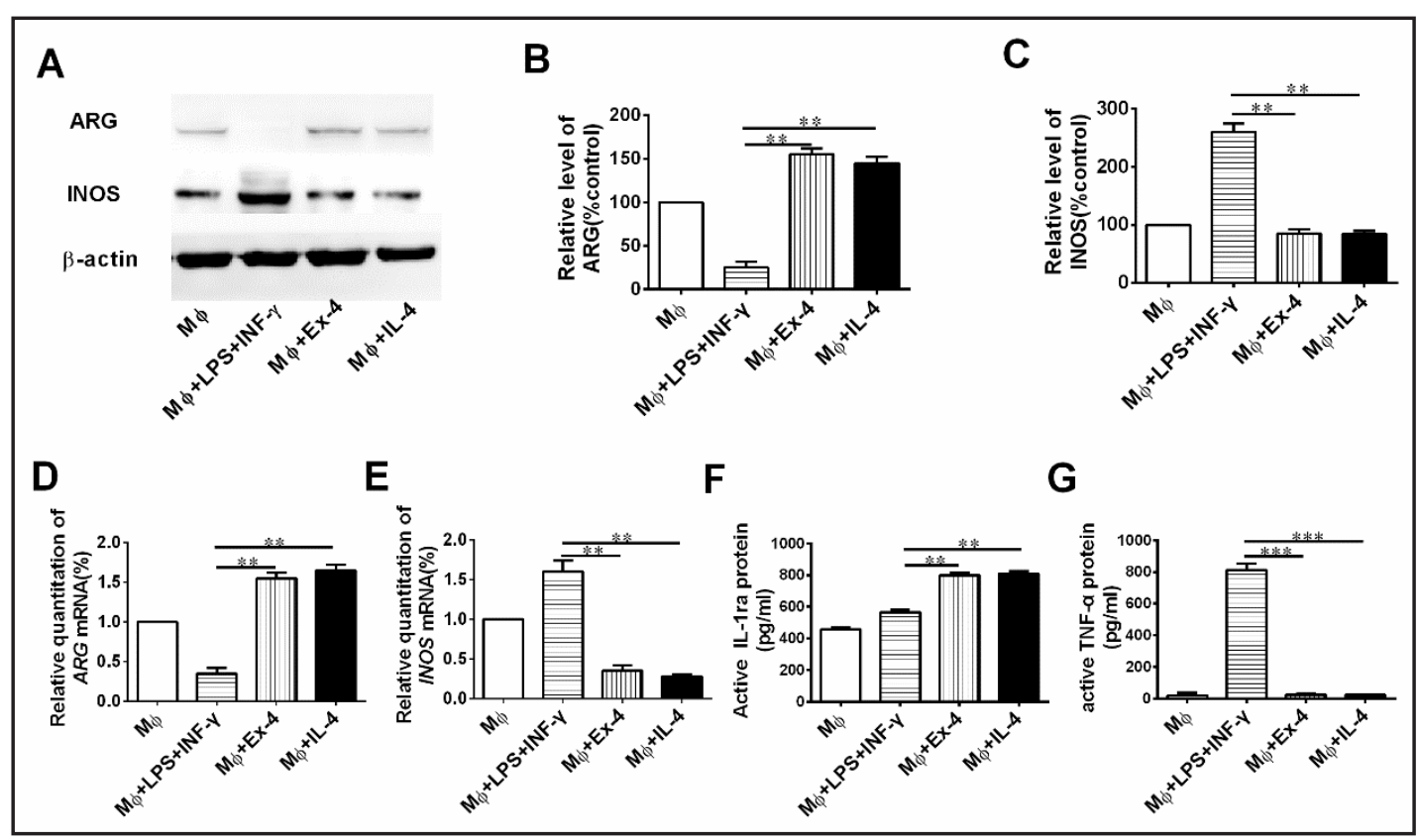

Fig. 4. Exendin-4 promoted the polarization of macrophages. (A-C) Western blot analysis of iNOS (M1 marker) and ARG (M2 marker) protein levels. (LPS+INF- $\gamma$ induced M1 polarization and IL-4 induced M2 polarization). ( $\mathrm{n}=3$ independent samples/group). (D,E) RT-PCR and ELISA (F,G) analyses the expression of the M1 or M2 markers from the above four groups ( $n=3$ independent samples/group). TNF- $\alpha$, tumor necrosis factor- $\alpha$; IL-1ra, IL-1 receptor antagonist. Data represent the mean \pm SD. Differences between groups were evaluated by one-way ANOVA followed by Student-Newman-Keuls t-test. ${ }^{*} \mathrm{P}<0.05,{ }^{* *} \mathrm{P}<0.01,{ }^{* * *} \mathrm{P}<0.001$.

Exendin-4 induces the polarization of BMDMs which secrete TGF- $\beta 1$ and promote BMSC migration to the bone surface

The dynamic phenotype of macrophages is regulated by different cytokines present in the microenvironment and can be polarized into M1 and M2 subtypes. To investigate the effect of Exendin-4 on macrophages, we analyzed the expression of ARG and iNOS as markers of M2 and M1 phenotypes in BMDMs by Western blotting and qRT-PCR (Fig. 4A-E). Western blot analysis showed that Exendin-4 increased ARG expression compared with macrophages group (M $\varphi$ ) and LPS+INF- $\gamma$ treated group. Furthermore, there was no significant difference in ARG expression between the macrophages treated with Exendin- 4 and those treated with IL-4. The expression of iNOS in both the Exendin-4 and IL-4 groups was lower than that in the LPS+INF- $\gamma$ group. TNF- $\alpha$ levels and IL-1ra levels were also determined by ELISA as markers of the M1 subtype and M2 subtypes, respectively (Fig. 4F, G). LPS+INF- $\gamma$ increased TNF- $\alpha$ expression compared with the other groups. In addition, Exendin- 4 and IL-4 increased IL1 ra expression compared with LPS+INF- $\gamma$ group. These results demonstrated that Exendin-4 induces macrophage polarization into the M2, not the M1 subtype.

Further studies were carried out to investigate the interaction between BMSCs and BMDMs treated with Exendin-4. Transwell migration assays were performed to confirm the effect of BMDMs on BMSCs. We found that the conditioned media from macrophages treated with IL-4 did not induce BMSCs migration compared with that in the macrophage group. In contrast, the conditioned media from macrophages treated with Exendin-4 induced migration of BMSCs (Fig. 5). The control group, LPS+INF- $\gamma$ group, IL-4 and Exendin-4 groups were used to exclude non-specific effects of the media, LPS+ INF- $\gamma$, IL-4 and Exendin- 4.

M2 subtype can be divided into M2a macrophages, which are stimulated by IL-4, M2b macrophages, which are stimulated by immune complexes (IC) and TLR or IL-1R agonists, and M2c macrophages, which are stimulated by IL-10. We found that the conditioned medium from the macrophages stimulated with Exendin-4 or IL-10 significantly increased numbers of BMSC migration than that induced by the conditioned medium from the macrophage groups 


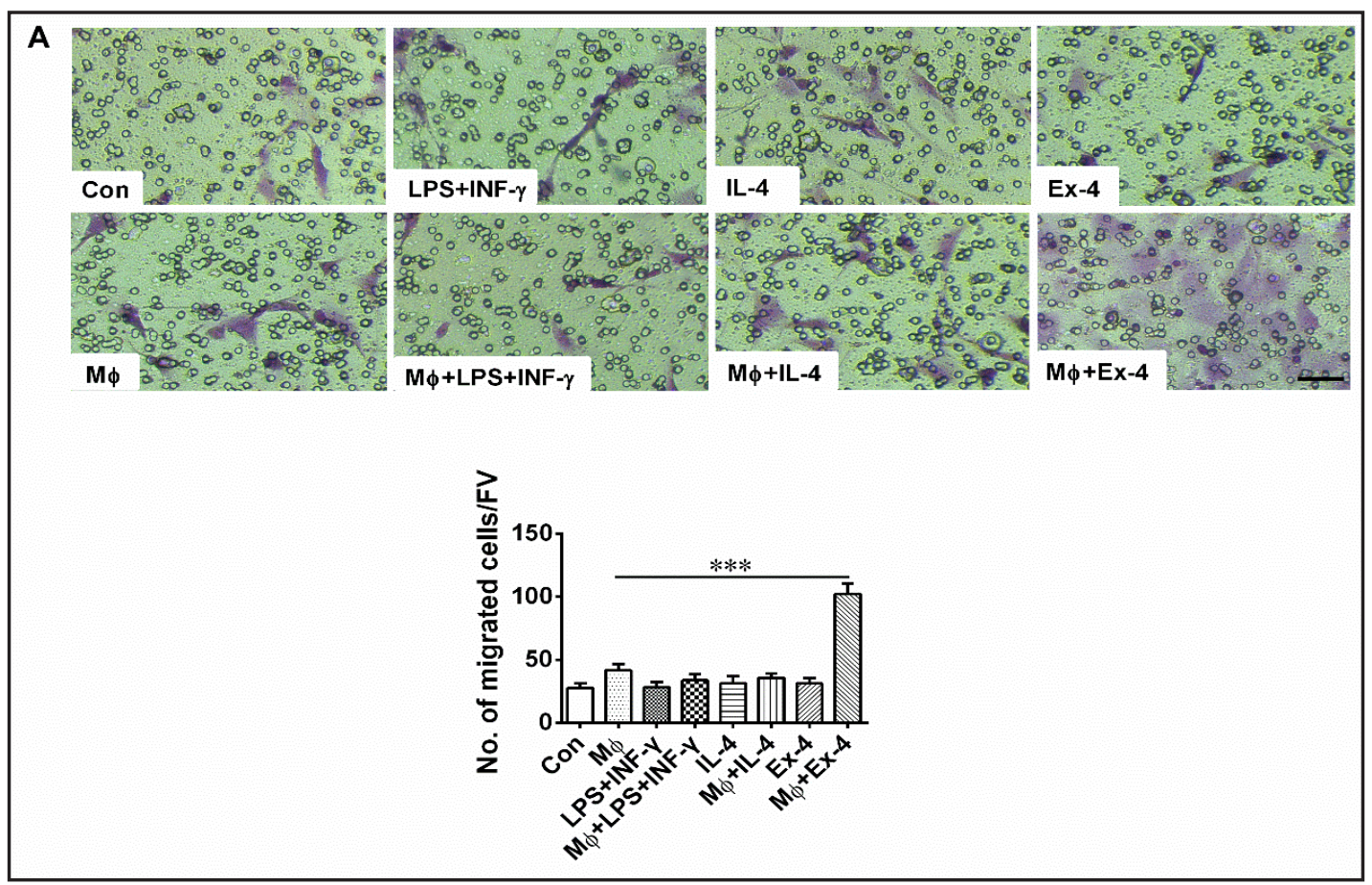

Fig. 5. Transwell assays for migration of mice BMSCs and the numbers of migrated cells from the corresponding groups. No. of migrated cells/FV, number of migrated cells per field of view. (con, control; $M \Phi$, macrophage). ( $\mathrm{n}=3$ /independent samples/group) Scale bars, $50 \mu \mathrm{m}$. Data represent mean $\pm \mathrm{SD},{ }^{*} \mathrm{P}<0.05$, ${ }^{* *} \mathrm{P}<0.01,{ }^{* * *} \mathrm{P}<0.001$, by one-way ANOVA followed by a Student-Newman-Keuls t-test.

(Fig. 6A, B). Moreover, Western blot analysis showed that IL-10 or Exendin-4 promoted the expression of TGF- $\beta 1$. In addition, ELISA analysis of TGF- $\beta 1$ levels in these conditioned media revealed that IL-10 or Exendin-4 stimulated macrophages to secrete TGF- $\beta 1$. These data indicated that Exendin-4 stimulates macrophages to secrete TGF- $\beta 1$, which induces the migration of BMSCs (Fig. 6C, D).

We then conducted further investigations to confirm that BMSC migration was due to TGF- $\beta 1$ secreted by macrophages stimulated by Exendin- 4 or IL-10 (Fig. 6E, F). The results showed that TGF- $\beta 1$ antibody-mediated neutralization significantly inhibited the migration of BMSCs induced by TGF- $\beta 1$ conditioned medium. Furthermore, the numbers of BMSCs induced to migrate by the conditioned media from macrophages treated with IL-10 or Exendin-4 were significantly decreased in the presence of the neutralizing anti-TGF- $\beta 1$ antibody. These findings indicated that active TGF- $\beta 1$ is the cytokine secreted by M2 subtype to induce BMSC migration. Taken together, these results showed that Exendin- 4 promoted the polarization of macrophages into M2 subtype to secret TGF- $\beta 1$ and induce BMSC migration.

\section{Mechanisms by which Exendin-4 stimulates macrophage polarization}

We used the GLP-1R siRNA or TGF- $\beta 1$ siRNA to investigate the effects GLP-1R and TGF- $\beta 1$ on BMSC migration. Based on previous reports, we analyzed GLP-1 receptor expression by macrophages derived from bone marrow [43]. Notably, PCR analysis confirmed that macrophages expressed the GLP-1 receptor gene (data not shown). Transwell experiments showed that the numbers of migrated BMSCs were decreased significantly by GLP-1R or TGF- $\beta 1$ knockdown (Fig. 7A-D).

However, as shown in our previous study, the cAMP/PKA and phosphatidylinositol 3-kinase (PI3K)/Akt signaling pathways are main two signaling pathways that are stimulated downstream of GLP-1R activation. Moreover, M2a macrophages are induced by IL-4 and IL13 through STAT6 phosphorylation, M2b macrophages are induced by the combination of IC and TLR or IL-1R agonists, and M2c macrophages are induced by IL-10 through STAT3 KARGER 


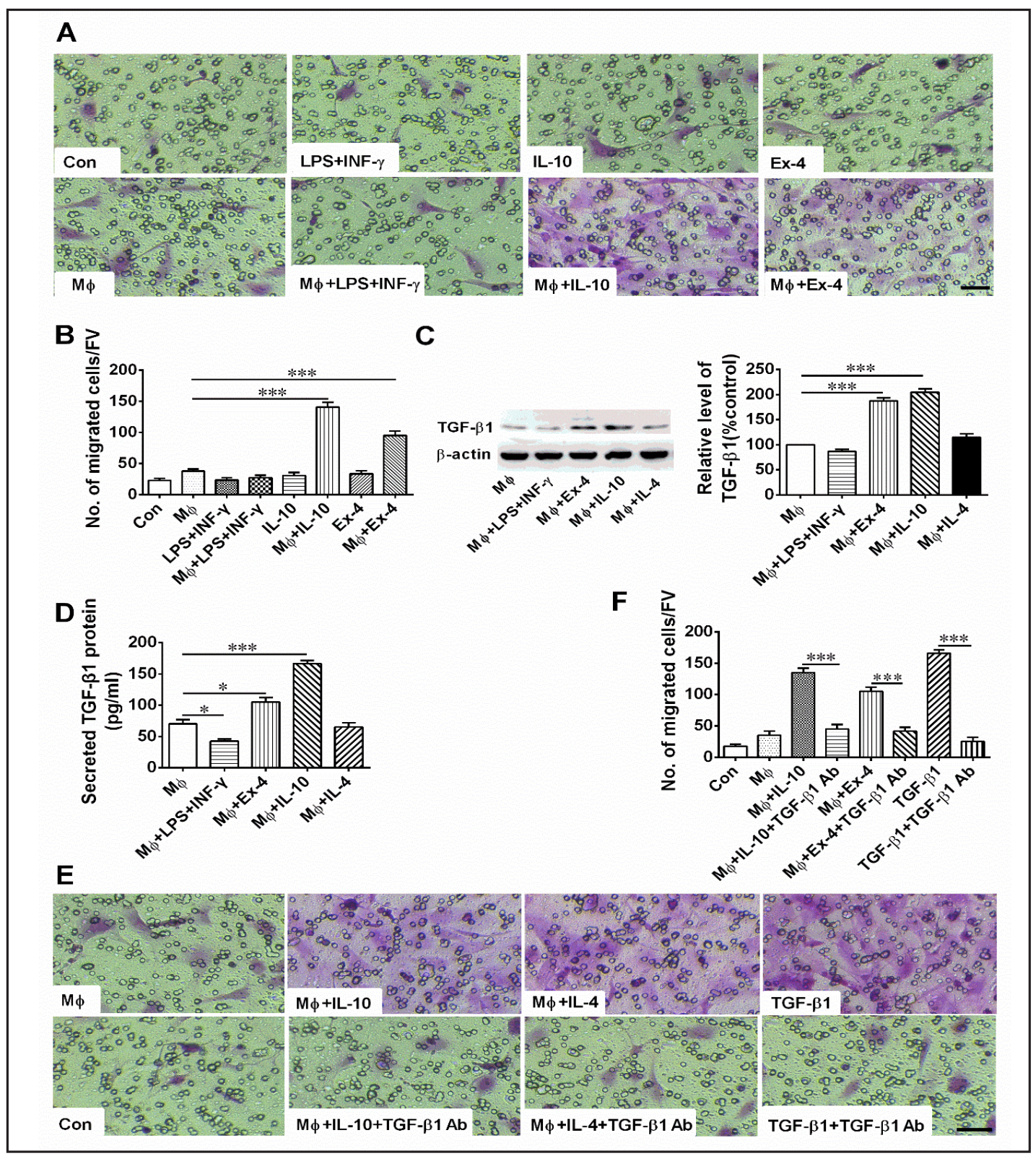

Fig. 6. M2 subtype secreted TGF- $\beta 1$ and induced BMSC migration. $(A, B)$ Transwell assays of migration of mice BMSCs and (B) the numbers of migrated cells from the corresponding groups $(\mathrm{n}=3$ independent samples/group). No. of migrated cells/FV, number of migrated cells per field of view; con, just medium; MФ, macrophage. Scale bars, $50 \mu \mathrm{m}$. (C,D) Western blot (C) and ELISA (D) analyses of TGF- $\beta 1$ expression ( $n=3$ independent samples/group). (E,F) Transwell assays of BMSC migration using conditioned medium with the addition of TGF- $\beta 1$ neutralizing antibodies ( $n=3$ independent samples/group). Ab, antibody; No. of migrated cells/FV, number of migrated cells per field of view. Scale bars, $50 \mu \mathrm{m}$. Data represent the mean \pm SD. Differences between groups were evaluated by one-way ANOVA followed by Student-Newman-Keuls t-test. $* \mathrm{P}<0.05,{ }^{* *} \mathrm{P}<0.01,{ }^{* * *} \mathrm{P}<0.001$.

phosphorylation. We analyzed ARG expression to identify the pathways involved GLP-1R signaling (Fig. 7E). PKA inhibitor, H-89, decreased ARG expression, while the PI3K inhibitor, wortmannin, and the mTOR inhibitor, rapamycin, did not decrease the expression of ARG. The results showed that Exendin-4 induced the polarization of macrophages via the PKA signaling pathway. IL-10 promotes M2 polarization through the induction of p50 NF- $\mathrm{BB}$

\section{KARGER}


homodimer, c-Maf, and STAT3 activities. Our results showed that H-89 inhibited STAT3 phosphorylation and TGF- $\beta 1$ expression (Fig. 7F). These results indicated that Exendin-4 induces macrophage polarization into the M2 subset via a cAMP/PKA-dependent signaling pathway and the STAT3 signaling pathway.

The GLP-1 receptor antagonist, Exendin(9-39), and the cAMP activator, Forskolin, were used to investigate the signaling pathways involved in macrophage polarization (Fig. 7F). The expression of P-STAT3 and TGF- $\beta 1$ in the Exendin- 4 treated group was higher than that in the group treated with $\mathrm{H}-89$, indicating that $\mathrm{H}-89$ inhibits polarization and the secretion of TGF- $\beta 1$ in macrophages. In addition, P-STAT3 expression was increased in the macrophages treated with Exendin-4 compared with that in macrophages treated with Exendin-4 and Exendin(9-39). Forskolin increased P-STAT3 expression, while H-89 attenuated the effect of forskolin. These results confirmed that Exendin-4 activates the polarization of macrophage into the M2 subset via the GLP-1 receptor signaling pathway. We performed co-immunoprecipitation studies to identify crosstalk between the GLP-1R pathway and the macrophage polarization pathways (Fig. 7G). PKA co-immunoprecipitated with P-STAT3 in macrophages treated with Exendin-4, indicating that Exendin-4 promotes macrophage polarization through the interaction between PKA and STAT3.

\section{Discussion}

The present study revealed that Exendin-4 induces BMDM secretion of TGF- $\beta 1$, which recruits BMSCs to the bone resorptive sites in a process that is vital for bone remodeling. Exendin-4 is a structural analog of GLP-1, which can promote bone formation in diabetesinduced bone loss. Some studies have shown that Exendin- 4 increases bone mineral density and induces osteogenesis in type 2 diabetic models [44, 45], with decreased risk of fracture [46] through promoting BMSC differentiation [47]. These studies indicated that Exendin-4 promotes osteoblast differentiation to increase bone formation. Furthermore, our previous studies also showed that Exendin-4 mediates its effects on bone formation via the PI3KAKT signaling pathway [48], although the source of BMSCs recruited to the bone resorptive sites was not clarified. However, our results showed that Exendin-4 increased the trabecular number and thickness and enhanced the rate of bone formation to promote bone mass, which is consistent with other reports [3]. Furthermore, Exendin-4 increased the expression of both Runx-2 and Osterix, which are markers of bone formation. Osteoblasts and osteoclasts are the two main cell-types involved in bone formation. Bone remodeling involves resorption of bone matrix by osteoclasts and cytokine release into the bone marrow. This leads to recruitment of BMSCS to the bone resorptive sites and differentiation into osteoblasts to promote bone formation. Osteoclasts play an important role in initial bone formation. The first step in bone remodeling involves absorption of bone marrow by osteoclasts with TGF- $\beta 1$ released to attract the BMSCs to the resorptive sites, where osteotropic factors stimulate osteoblast differentiation [4]. Furthermore, Hao [49] reported that Exendin-4 promotes the migration of BMSCs via the PI3K/AKT signaling pathway. However, since the half-lives of Exendin-4 and GLP-1 are relatively short, it is necessary to determine the continuous effect of Exendin-4 or GLP-1 on the migration of BMSCs. Therefore, we carried out further experiments to investigate this issue. As TGF- $\beta 1$ induces the migration of BMSCs to the bone surface, we plan to explore the relationship between Exendin- 4 and TGF- $\beta 1$ in future studies. Our previous study showed that Exendin-4 induces the differentiation of BMSCs into osteoblasts. In this study, we found greater numbers of BMSCs on the bone surface in OVX mice compared with that in the control mice, while there were fewer osteoblasts on the bone surface in the OVX mice compared with that in the control mice. Although the mechanisms are unknown, Exendin-4 has been reported to function as an osteotropic factor to induce differentiation of BMSC into osteoblasts [48]. In accordance with these reports, we found that Exendin-4 increased BMSC migration to the bone surface in the OVX mice compared with that in the OVX mice, which indicates that Exendin-4 induces BMSC migrations to the bone 


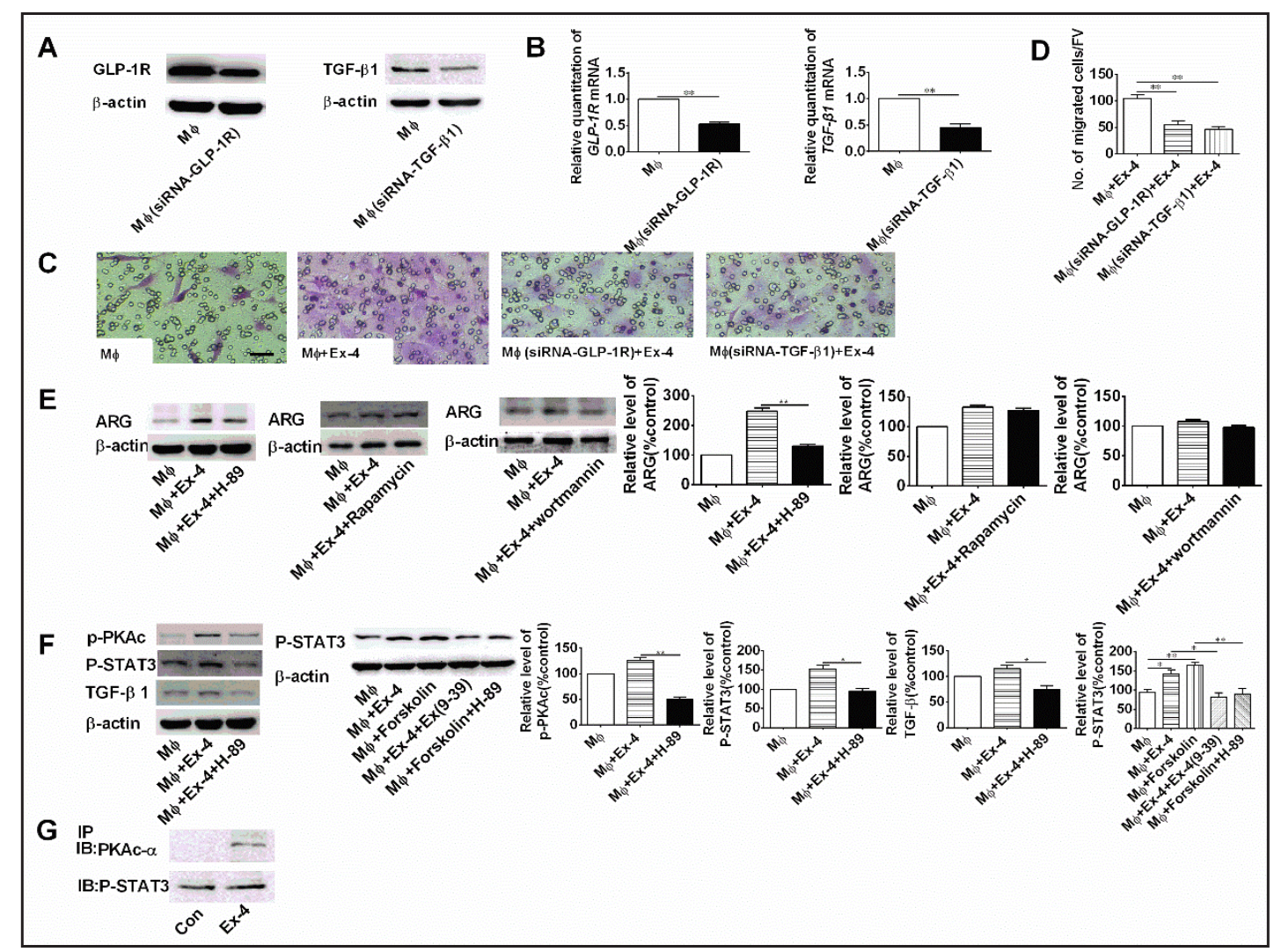

Fig. 7. Exendin-4 induced macrophage polarization via the PKA-STAT3 signaling pathway. (A, B) Protein and gene expression of GLP-1R or TGF- $\beta 1$ in macrophages treated with GLP-1R siRNA or TGF- $\beta 1$ siRNA. (C-D) Transwell assays of mouse BMSC migration and the numbers of migrated cells in the corresponding groups ( $\mathrm{n}=3$ independent samples/group). No. of migrated cells/FV, number of migrated cells per field of view; MФ, macrophage. Scale bars, $50 \mu \mathrm{m}$. (E) Western blot analysis of ARG protein level ( $\mathrm{n}=3$ independent samples/group). H-89, PKA inhibitor; wortmannin, PI3K inhibitor; rapamycin, mTOR inhibitor. (F) Western blot analysis of catalytic PKA (PKAc), phosphorylated STAT3 and TGF- $\beta 1$ protein levels in macrophages following different treatments: Exendin-4 and H-89 ( $n=3$ independent samples/group). Western blot analysis of phosphorylated STAT3 protein levels in macrophages following different treatments: Exendin-4, forskolin (adenylate cyclase activator), forskolin+H-89, Exendin-4+Exendin(9-39) (GLP-1 receptor antagonist) and Exendin-4+Ex(9-39)+forskolin ( $\mathrm{n}=3$ independent samples/group). (G) Immunoprecipitation and Western blot analysis of interaction between PKA and STAT3 in the cytoplasm of macrophages after Exendin-4 treatment. Data represent the mean \pm SD. Differences between groups were evaluated by one-way ANOVA followed by Student-Newman-Keuls t-test. ${ }^{*} \mathrm{P}<0.05,{ }^{* *} \mathrm{P}<0.01$.

surface. IHC analysis of bone slices showed increased numbers of osteoblasts and BMSCs on the bone surface in the Exendin-4 treated mice compared with those in OVX and control mice. These observations suggest that Exendin- 4 not only promotes the differentiation of BMSCs into osteoblasts, but also induces the migration of BMSCs to the bone surface although the mechanisms are unclear. TGF- $\beta 1$ is one of the most important cytokines in the bone matrix and has been shown to induce migration of BMSCs to the bone surface and regulate proliferation. Our results showed that TGF- $\beta 1$ expression was higher in OVX mice compared to the levels detected in the control mice because of the high activation of osteoclasts. However, the expression of TGF- $\beta 1$ in OVX mice was lower than that in the mice treated with Exendin-4, indicating that Exendin-4 increases TGF- $\beta 1$ expression; however, the underlying mechanism remains to be elucidated.

TRAP staining revealed greater numbers of osteoclasts in OVX mice than in the Exendin-4 treated mice, suggesting that higher levels of TGF- $\beta 1$ are released into bone marrow in OVX 
mice compared with that in the Exendin-4 treated mice. Surprisingly, the opposite pattern was observed in this study, with higher levels of TGF- $\beta 1$ in Exendin- 4 treated mice than that in OVX mice. The mechanisms underlying this phenomenon are unknown.

Bone formation is a complex process involving osteoblasts, osteoclasts and monocytes, such as preosteoclasts and macrophages [11,31,32]. Osteomacs represent a population of macrophages that are resident in the bone tissues and derived from primordial hematopoietic progenitors that exert pro-anabolic effects on osteoblasts $[32,50]$. In contrast, BMDM are derived from blood monocytes following tissue injury and infection. A study conducted in a cranial defect model showed that BMDM were associated with anabolic responses and biomaterial-induced osteogenesis [32, 51, 52]. Polarization of macrophages toward either the M1 or M2 subset phenotype is likely to affect the bone formation and current data indicate that this process is influenced directly or indirectly by their microenvironment [39]. Osteomacs have been shown to induce bone formation in mouse tibial injury and to regulate osteoblast fuction [31, 32]. In this study, we investigated the function of BMDM on bone formation in OVX mice. Our results revealed fewer BMDMs in the trabecular bone in OVX mice compared with that in the Exendin- 4 treated mice, which suggested that BMDMs may affect bone formation. Currently, there are two methods to deplete macrophages. One is conditional depletion of macrophages in MAFIA mice, in which macrophage apoptosis is induced via the Fas-FasL pathway and the other involves the induction of apoptosis following phagocytosis of clodronate liposomes administered to the mice. Neither of these methods results in complete knockout of all macrophages and all macrophage subtypes are targeted equally. In this study, we depleted macrophages by administration of clodronate liposomes to evaluate their role in bone formation in OVX mice. Micro-CT analysis of trabecular bone structure showed that the bone volume, trabecular number and trabecular thickness in clodronate liposome-treated OVX mice was lower than that in OVX mice, which indicated that BMDMs affect bone formation, although the mechanisms are unknown. The bone volume and trabecular numbers in macrophage-depleted OVX mice treated with Exendin-4 were higher than those in OVX mice treated with clodronate liposomes alone because Exendin-4 promotes BMSC differentiation into osteoblasts. Moreover, IHC analysis showed decreased TGF- $\beta 1$ expression at the bone surface in the macrophage-depleted groups compared with that in the OVX and Exendin-4 groups. These results indicate that Exendin-4 induces macrophage secretion of TGF- $\beta 1$ which promotes BMSC migration to the bone surface. Macrophages can be stimulated to differentiate into M1 and M2 subsets according to different microenvironments. The M1 subset is characterized by secretion of pro-inflammatory cytokines, while the M2 subset produces anti-inflammatory cytokines. Recently, it has been reported that conditional depletion of macrophages in MAFIA mouse bone retarded skeletal growth and resulted in osteoporosis. Furthermore, fracture healing was impaired in the transgenic mice or clodronate liposome-treated mice. In addition, macrophages can affect osteoblastic differentiation of BMSCs and the M2 subtype is beneficial for bone formation. Thus, the balance in M1/M2 macrophage function is critical for fracture healing [30, 53], although the precise macrophage subtype is open to discussion and the mechanisms of the osteogenesis remain to be elucidated. Further investigations are required to determine which subpopulation influences osteogenesis in the OVX model and Exendin-4 treated mice.

To investigate the effect of Exendin- 4 on the polarization of macrophages, we stimulated macrophages with Exendin-4, IL-4 or LPS+INF- $\gamma$. Our results showed that Exendin-4 increased the expression of ARG and inhibited iNOS expression at both the mRNA and protein levels, with the same effect observed following treatment with IL-4. These observations indicate that Exendin-4 promotes macrophage polarization to the M2 subset and inhibits macrophage polarization to the M1 subset. Moreover, ELISA data revealed that macrophages treated with Exendin-4 or IL-4 secreted higher levels of IL-1ra than untreated macrophages or those treated with LPS+INF- $\gamma$. As Exendin-4 promoted M2 polarization of macrophages, we investigated the interaction between M2 macrophages and BMSCs. Macrophages can be divided into two subtypes: M1 and M2, which is further subdivided into three subsets: M2a, M2b and M2c. First, we determined the effect of the conditioned medium from macrophages 
treated with IL-4 or Exendin-4 on BMSC migration. There was no significant difference in the number of migrated BMSCS following treatment with conditioned medium from macrophages treated with and without IL-4, while there were fewer migrated BMSCs following treatment with conditioned medium from macrophages treated with Exendin-4. This indicates that Exendin-4 treatment induces the secretion of different cytokines. However, the conditioned medium derived from macrophages treated with IL-10 or Exendin-4 induced migration of a greater number of BMSCs into the lower chamber than that from untreated macrophages, suggesting that IL-10 or Exendin-4 could induce macrophages to secrete the same cytokines. IL-10 stimulates macrophages polarization into the M2c subset, which secretes TGF- $\beta 1$. Western blot analysis showed that Exendin-4 promoted the expression of TGF- $\beta 1$, in a similar manner to IL-10. Furthermore, ELISA data also showed that macrophages treated with IL-10 or Exendin-4 secreted higher levels of TGF- $\beta 1$ than untreated macrophages. These results suggest that Exendin-4 induces the polarization of macrophages into the M2c subset and secretion of TGF- $\beta 1$, although the mechanisms are unknown.

Further studies were carried out to confirm that the TGF- $\beta 1$ was secreted by the M 2 subset and to investigate the effect of TGF- $\beta 1$ on BMSC migration. A TGF- $\beta 1$ antibody neutralized the effect of TGF- $\beta 1$ on the migration of BMSCs. Transwell experiment data showed that the neutralizing TGF- $\beta 1$ antibody decreased the numbers of migrated BMSCs when cultured in the conditioned medium derived from macrophages treated with IL-10 or Exendin-4. This confirms that BMSC migration is induced by TGF- $\beta 1$ secreted by macrophages; however, the mechanism by which Exendin-4 promotes the expression of TGF- $\beta 1$ in macrophages is unknown. Osteal macrophages have been shown to promote bone healing and osteoblast mineralization, although the mechanisms by which macrophages regulate bone formation remain to be elucidated $[31,32,54]$. Our data showed that BMDMs secrete TGF- $\beta 1$ at the bone surface to induce BMSCs migration to the bone surface.

To investigate the effect of GLP-1R and TGF- $\beta 1$ on BMSC migration, we generated stable cell lines with GLP-1R and TGF- $\beta 1$ knockdown. GLP-1R or TGF- $\beta 1$ knockdown induced a significant decrease in the number of migrated BMSCs in the two groups compared with those observed in cultures with conditioned medium derived from macrophages treated with Exendin-4. These observations indicate that GLP-1R or TGF- $\beta 1$ play an important role in the effects of Exendin- 4 .

To further investigate the mechanisms underlying the effects of Exendin-4 on macrophage polarization, we used specific inhibitors of the GLP-1R signaling pathway. The results showed that the PKA inhibitor H-89 repressed ARG expression by macrophages treated with Exendin-4, indicating that Exendin-4 stimulates the polarization of macrophages via the PKA signaling pathway. The major pathways responsible for macrophage polarization involve a balance between activation of STAT1 and STAT3/STAT6. The predominance of STAT3 and STAT6 activation results in M2 macrophage polarization, associated with immune suppression and tumor progression. IL-4-induced c-Myc activity controls a subset of M2-associated genes. IL-4 also induces the M2-polarizing Jmjd3-IRF4 axis to inhibit IRF5-mediated M1 polarization. IL-10 stimulates M2 polarization via STAT3 signaling pathway induction of the expression of genes and proteins, such as IL-10, TGF- $\beta 1$ and MRC-1[33]. Notably, we found that H-89 inhibited the expression of P-STAT3 and TGF- $\beta 1$ in macrophages treated with Exendin-4. Moreover, PKA was co-immunoprecipitated with STAT3 in macrophages treated with Exendin-4, indicating that Exendin-4 promotes macrophage polarization to the M2 subtype through the interaction between PKA and STAT3. These data indicate that Exendin-4 promotes BMSC migration into resorptive sites by inducing the polarization of macrophages into the M2 subtype through signaling crosstalk between GLP-1R signaling and STAT3 signaling, and that the M2 macrophages generated secrete TGF- $\beta 1$ to promote osteogenesis. Our results indicate the potential of Exendin-4 as a therapeutic agent for preventing bone loss and promoting bone formation by promoting M2 polarization of macrophages. Furthermore, this is the first demonstration that Exendin-4 induces the polarization of BMDMs into the M2 subtype via the PKA-STAT3 signaling pathway to induce the migration of BMSCs. In summary, we found that Exendin- 4 induces TGF- $\beta 1$ secretion by 


\section{Cellular Physiology Cell Physiol Biochem 2017;44:1696-1714 \begin{tabular}{ll|l} 
and Biochemistry & $\begin{array}{l}\text { DOI: 10.1159/000485776 } \\
\text { Published online: December 06, } 2017\end{array}$ & $\begin{array}{l}\text { C } 2017 \text { The Author(s). Published by S. Karger AG, Basel } \\
\text { www.karger.com/cpb }\end{array}$ \\
\hline
\end{tabular}}

Wang et al.: Exendin-4 Induces BMSC Migration Via BMDM Polarization

BMDMs and Exendin-4 promotes BMSC migration to the bone surface via the polarization of macrophages to the M2 subtype through the PKA-STAT3 signaling pathway.

\section{Acknowledgements}

Authors' roles: Study design: NW and JRM. Study conduct: NW, JG, FY. Data collection: NW, JG, JRM, and ZXL. Data analysis: NW, JG, XM, MJ, and FD. Data interpretation: FD, FY, NW, XM, and YZ. Drafting manuscript: YZ, GHH and MKL. Revising manuscript content: NW, JRM, XM and XXL. Final manuscript approval: NW, JG, MJ, and XXL. XXL and JRM take responsibility for the integrity of the data analysis. This research was supported by the grants from the National Natural Science Foundation of China (No. 81471093, 81571278, 81402931, 81460560) and the Natural Science Foundation of Shaanxi Province (No. 2015JM8421).

\section{Disclosure Statement}

The authors declare that they have no competing interests.

\section{References}

1 Teitelbaum SL: Bone resorption by osteoclasts. Science 2000;289:1504-1508.

-2 Zaidi M: Skeletal remodeling in health and disease. Nat Med 2007;13:791-801.

3 Ma X, Meng J, Jia M, Bi L, Zhou Y, Wang Y, Hu J, He G, Luo X: Exendin-4, a glucagon-like peptide-1 receptor agonist, prevents osteopenia by promoting bone formation and suppressing bone resorption in aged ovariectomized rats. J Bone Miner Res 2013;28:1641-1652.

4 Wu X, Pang L, Lei W, Lu W, Li J, Li Z, Frassica FJ, Chen X, Wan M, Cao X: Inhibition of Sca-1-positive skeletal stem cell recruitment by alendronate blunts the anabolic effects of parathyroid hormone on bone remodeling. Cell Stem Cell 2010;7:571-580.

5 Cranney A, Wells G, Willan A, Griffith L, Zytaruk N, Robinson V, Black D, Adachi J, Shea B, Tugwell P, Guyatt G, Osteoporosis Methodology G, The Osteoporosis Research Advisory G: Meta-analyses of therapies for postmenopausal osteoporosis. II. Meta-analysis of alendronate for the treatment of postmenopausal women. Endocr Rev 2002;23:508-516.

6 Orwoll ES, Scheele WH, Paul S, Adami S, Syversen U, Diez-Perez A, Kaufman JM, Clancy AD, Gaich GA: The effect of teriparatide [human parathyroid hormone (1-34)] therapy on bone density in men with osteoporosis. J Bone Miner Res 2003;18:9-17.

7 Black DM, Greenspan SL, Ensrud KE, Palermo L, McGowan JA, Lang TF, Garnero P, Bouxsein ML, Bilezikian JP, Rosen CJ, Pa THSI: The effects of parathyroid hormone and alendronate alone or in combination in postmenopausal osteoporosis. N Engl J Med 2003;349:1207-1215.

8 Xian L, Wu X, Pang L, Lou M, Rosen CJ, Qiu T, Crane J, Frassica F, Zhang L, Rodriguez JP, Xiaofeng J, Shoshana Y, Shouhong X, Argiris E, Mei W, Xu C: Matrix IGF-1 maintains bone mass by activation of mTOR in mesenchymal stem cells. Nat Med 2012;18:1095-1101.

-9 Tang Y, Wu X, Lei W, Pang L, Wan C, Shi Z, Zhao L, Nagy TR, Peng X, Hu J, Feng X, Van Hul W, Wan M, Cao X: TGF-beta1-induced migration of bone mesenchymal stem cells couples bone resorption with formation. Nat Med 2009;15:757-765.

10 Zhen G, Wen C, Jia X, Li Y, Crane JL, Mears SC, Askin FB, Frassica FJ, Chang W, Yao J, Carrino JA, Cosgarea A, Artemov D, Chen Q Zhao Z, Zhou X, Riley L, Sponseller P, Wan M, Lu WW, Cao X: Inhibition of TGF-beta signaling in mesenchymal stem cells of subchondral bone attenuates osteoarthritis. Nat Med 2013;19:704712.

11 Xie H, Cui Z, Wang L, Xia Z, Hu Y, Xian L, Li C, Xie L, Crane J, Wan M, Zhen G, Bian Q, Yu B, Chang W, Qiu T, Pickarski M, Duong LT, Windle JJ, Luo X, Liao E, Cao X: PDGF-BB secreted by preosteoclasts induces angiogenesis during coupling with osteogenesis. Nat Med 2014;20:1270-1278.

12 Gao P, Zhou Y, Xian L, Li C, Xu T, Plunkett B, Huang SK, Wan M, Cao X: Functional effects of TGF-beta1 on mesenchymal stem cell mobilization in cockroach allergen-induced asthma. J Immunol 2014;192:45604570 . 


\section{Cellular Physiology Cell Physiol Biochem 2017;44:1696-1714 \begin{tabular}{ll|l} 
and Biochemistry & $\begin{array}{l}\text { DOI: 10.1159/000485776 } \\
\text { Published online: December 06, } 2017\end{array}$ & $\begin{array}{l}\text { C } 2017 \text { The Author(s). Published by S. Karger AG, Basel } \\
\text { www.karger.com/cpb }\end{array}$ \\
\hline
\end{tabular}}

13 Cui Z, Crane J, Xie H, Jin X, Zhen G, Li C, Xie L, Wang L, Bian Q, Qiu T, Wan M, Xie M, Ding S, Yu B, Cao X: Halofuginone attenuates osteoarthritis by inhibition of TGF-beta activity and H-type vessel formation in subchondral bone. Ann Rheum Dis 2016;75:1714-1721.

14 Zhen G, Cao X: Targeting TGFbeta signaling in subchondral bone and articular cartilage homeostasis. Trends Pharmacol Sci 2014;35:227-236.

15 Liu S, Song W, Boulanger JH, Tang W, Sabbagh Y, Kelley B, Gotschall R, Ryan S, Phillips L, Malley K, Cao X, Xia TH, Zhen G, Cao X, Ling H, Dechow PC, Bellido TM, Ledbetter SR, Schiavi SC: Role of TGF-beta in a mouse model of high turnover renal osteodystrophy. J Bone Miner Res 2014;29:1141-1157.

16 Wang L, Xie L, Tintani F, Xie H, Li C, Cui Z, Wan M, Zu X, Qi L, Cao X: Aberrant Transforming Growth Factorbeta Activation Recruits Mesenchymal Stem Cells During Prostatic Hyperplasia. Stem Cells Transl Med 2016;10.5966/sctm.2015-0411

17 Hughes DE, Dai A, Tiffee JC, Li HH, Mundy GR, Boyce BF: Estrogen promotes apoptosis of murine osteoclasts mediated by TGF-beta. Nat Med 1996;2:1132-1136.

18 Iwai T, Ito S, Tanimitsu K, Udagawa S, Oka J: Glucagon-like peptide-1 inhibits LPS-induced IL-1beta production in cultured rat astrocytes. Neurosci Res 2006;55:352-360.

19 Cai Y, Hu X, Yi B, Zhang T, Wen Z: Glucagon-like peptide-1 receptor agonist protects against hyperglycemiainduced cardiocytes injury by inhibiting high mobility group box 1 expression. Mol Biol Rep 2012;39:10705-10711.

20 Sun HX, Lu N, Liu DM, Zhao L, Sun LH, Zhao HY, Liu JM, Tao B: The bone-preserving effects of exendin-4 in ovariectomized rats. Endocrine 2016;51:323-332.

21 Lu N, Sun H, Yu J, Wang X, Liu D, Zhao L, Sun L, Zhao H, Tao B, Liu J: Glucagon-like peptide-1 receptor agonist Liraglutide has anabolic bone effects in ovariectomized rats without diabetes. PLoS One 2015;10:e0132744.

-22 Jiang YQ, Chang GL, Wang Y, Zhang DY, Cao L, Liu J: Geniposide Prevents Hypoxia/Reoxygenation-Induced Apoptosis in H9c2 Cells: Improvement of Mitochondrial Dysfunction and Activation of GLP-1R and the PI3K/AKT Signaling Pathway. Cell Physiol Biochem 2016;39:407-421.

23 Wang C, Chen X, Ding X, He Y, Gu C, Zhou L: Exendin-4 Promotes Beta Cell Proliferation via PI3k/Akt Signalling Pathway. Cell Physiol Biochem 2015;35:2223-2232.

24 Loi F, Cordova LA, Zhang R, Pajarinen J, Lin TH, Goodman SB, Yao Z: The effects of immunomodulation by macrophage subsets on osteogenesis in vitro. Stem Cell Res Ther 2016;7:15.

-25 Raggatt LJ, Wullschleger ME, Alexander KA, Wu AC, Millard SM, Kaur S, Maugham ML, Gregory LS, Steck R, Pettit AR: Fracture healing via periosteal callus formation requires macrophages for both initiation and progression of early endochondral ossification. Am J Pathol 2014;184:3192-3204.

-26 Nich C, Takakubo Y, Pajarinen J, Ainola M, Salem A, Sillat T, Rao AJ, Raska M, Tamaki Y, Takagi M, Konttinen YT, Goodman SB, Gallo J: Macrophages-Key cells in the response to wear debris from joint replacements. J Biomed Mater Res A 2013;101:3033-3045.

-27 Schindeler A, McDonald MM, Bokko P, Little DG: Bone remodeling during fracture repair: The cellular picture. Semin Cell Dev Biol 2008;19:459-466.

28 Dimmen S, Nordsletten L, Madsen JE: Parecoxib and indomethacin delay early fracture healing: a study in rats. Clin Orthop Relat Res 2009;467:1992-1999.

29 Schmidt-Bleek K, Schell H, Schulz N, Hoff P, Perka C, Buttgereit F, Volk HD, Lienau J, Duda GN: Inflammatory phase of bone healing initiates the regenerative healing cascade. Cell Tissue Res 2012;347:567-573.

30 Vi L, Baht GS, Whetstone H, Ng A, Wei Q, Poon R, Mylvaganam S, Grynpas M, Alman BA: Macrophages promote osteoblastic differentiation in-vivo: implications in fracture repair and bone homeostasis. J Bone Miner Res 2015;30:1090-1102.

-31 Alexander KA, Chang MK, Maylin ER, Kohler T, Muller R, Wu AC, Van Rooijen N, Sweet MJ, Hume DA, Raggatt LJ, Pettit AR: Osteal macrophages promote in vivo intramembranous bone healing in a mouse tibial injury model. J Bone Miner Res 2011;26:1517-1532.

-32 Chang MK, Raggatt LJ, Alexander KA, Kuliwaba JS, Fazzalari NL, Schroder K, Maylin ER, Ripoll VM, Hume DA, Pettit AR: Osteal Tissue Macrophages Are Intercalated throughout Human and Mouse Bone Lining Tissues and Regulate Osteoblast Function In vitro and In vivo. J Immunol 2008;181:1232-1244.

-33 Sica A, Mantovani A: Macrophage plasticity and polarization: in vivo veritas. J Clin Invest 2012;122:787795. 


\section{Cellular Physiology Cell Physiol Biochem 2017;44:1696-1714 \begin{tabular}{l|l} 
and Biochemistry Publisneg 10.1159/000485776 & $\begin{array}{l}\text { (c) } 2017 \text { The Author(s). Published by S. Karger AG, Basel } \\
\text { www.karger.com/cpb }\end{array}$
\end{tabular}

34 Gordon S, Martinez FO: Alternative activation of macrophages: mechanism and functions. Immunity 2010;32:593-604.

-35 Biswas SK, Mantovani A: Macrophage plasticity and interaction with lymphocyte subsets: cancer as a paradigm. Nat Immunol 2010;11:889-896.

-36 Mosser DM, Edwards JP: Exploring the full spectrum of macrophage activation. Nat Rev Immunol 2008;8:958-969.

37 Zhou D, Huang C, Lin Z, Zhan S, Kong L, Fang C, Li J: Macrophage polarization and function with emphasis on the evolving roles of coordinated regulation of cellular signaling pathways. Cell Signal 2014;26:192-197.

-38 Purdue PE: Alternative macrophage activation in periprosthetic osteolysis. Autoimmunity 2008;41:212217.

39 Murray PJ, Allen JE, Biswas SK, Fisher EA, Gilroy DW, Goerdt S, Gordon S, Hamilton JA, Ivashkiv LB, Lawrence T, Locati M, Mantovani A, Martinez FO, Mege JL, Mosser DM, Natoli G, Saeij JP, Schultze JL, Shirey KA, Sica A, Suttles J, Udalova I, van Ginderachter JA, Vogel SN, Wynn TA: Macrophage activation and polarization: nomenclature and experimental guidelines. Immunity 2014;41:14-20.

40 Mantovani A, Sica A, Sozzani S, Allavena P, Vecchi A, Locati M: The chemokine system in diverse forms of macrophage activation and polarization. Trends Immunol 2004;25:677-686.

41 Miron RJ, Bosshardt DD: OsteoMacs: Key players around bone biomaterials. Biomaterials 2016;82:1-19.

42 Dai Y, Dai D, Wang X, Ding Z, Mehta JL: DPP-4 inhibitors repress NLRP3 inflammasome and interleukin1 beta via GLP-1 receptor in macrophages through protein kinase C pathway. Cardiovasc Drugs Ther 2014;28:425-432.

43 Tanaka M, Matsuo Y, Yamakage H, Masuda S, Terada Y, Muranaka K, Wada H, Hasegawa K, Shimatsu A, Satoh-Asahara N: Differential effects of GLP-1 receptor agonist on foam cell formation in monocytes between non-obese and obese subjects. Metabolism 2016;65:1-11.

44 Kim JY, Lee SK, Jo KJ, Song DY, Lim DM, Park KY, Bonewald LF, Kim BJ: Exendin-4 increases bone mineral density in type 2 diabetic OLETF rats potentially through the down-regulation of SOST/sclerostin in osteocytes. Life Sci 2013;92:533-540.

-45 Nuche-Berenguer B, Moreno P, Portal-Nunez S, Dapia S, Esbrit P, Villanueva-Penacarrillo ML: Exendin-4 exerts osteogenic actions in insulin-resistant and type 2 diabetic states. Regul Pept 2010;159:61-66.

-46 Driessen JH, van Onzenoort HA, Starup-Linde J, Henry R, Burden AM, Neef C, van den Bergh JP, Vestergaard P, de Vries F: Use of Glucagon-Like-Peptide 1 Receptor Agonists and Risk of Fracture as Compared to Use of Other Anti-hyperglycemic Drugs. Calcif Tissue Int 2015;97:506-515.

-47 Fereshteh Nejad-Dehbashi MS, Mahmoud Hashemitabar, Ph.D.1, Mahmoud Orazizadeh, Ph.D.1, 2, Somaieh Bahramzadeh, M.Sc.1, Elham Shahhosseini Pourshoushtary, M.Sc.1, Layasadat Khorsandi, Ph.D.1, 2*: The Effects of Exendine-4 on Insulin Producing Cell Differentiation from Rat Bone Marrow-Derived Mesenchymal Stem Cells. Cell Journal 2014;16:187-194.

48 Meng J, Ma X, Wang N, Jia M, Bi L, Wang Y, Li M, Zhang H, Xue X, Hou Z, Zhou Y, Yu Z, He G, Luo X: Activation of GLP-1 Receptor Promotes Bone Marrow Stromal Cell Osteogenic Differentiation through beta-Catenin. Stem Cell Reports 2016;6:579-591.

49 Zhou H, Li D, Shi C, Xin T, Yang J, Zhou Y, Hu S, Tian F, Wang J, Chen Y: Effects of Exendin-4 on bone marrow mesenchymal stem cell proliferation, migration and apoptosis in vitro. Sci Rep 2015;5:12898.

50 Schulz C, Gomez Perdiguero E, Chorro L, Szabo-Rogers H, Cagnard N, Kierdorf K, Prinz M, Wu B, Jacobsen SE, Pollard JW, Frampton J, Liu KJ, Geissmann F: A lineage of myeloid cells independent of Myb and hematopoietic stem cells. Science 2012;336:86-90.

-51 Lyons FG, Al-Munajjed AA, Kieran SM, Toner ME, Murphy CM, Duffy GP, O’Brien FJ: The healing of bony defects by cell-free collagen-based scaffolds compared to stem cell-seeded tissue engineered constructs. Biomaterials 2010;31:9232-9243.

52 Chen Z, Wu C, Gu W, Klein T, Crawford R, Xiao Y: Osteogenic differentiation of bone marrow MSCs by betatricalcium phosphate stimulating macrophages via BMP2 signalling pathway. Biomaterials 2014;35:15071518.

53 Schlundt C, El Khassawna T, Serra A, Dienelt A, Wendler S, Schell H, van Rooijen N, Radbruch A, Lucius R, Hartmann S, Duda GN, Schmidt-Bleek K: Macrophages in bone fracture healing: Their essential role in endochondral ossification. Bone 2015;10.1016/j.bone.2015.10.019

54 Pettit AR, Chang MK, Hume DA, Raggatt LJ: Osteal macrophages: a new twist on coupling during bone dynamics. Bone 2008;43:976-982. 